\title{
PENGARUH SESAAT BRISK WALKING TERHADAP PENURUNAN TEKANAN INTRAOKULER ORANG DEWASA MUDA NON GLAUKOMA
}

\author{
Shane H. R. Ticoalu \\ Bagian Anatomi-Histologi Fakultas Kedokteran Universitas Sam Ratulangi Manado \\ Email: shartic19@yahoo.com
}

\begin{abstract}
The aims of this research were: 1) to find out the immediate effect of brisk walking on reducing intraocular pressures (IOPs) of non-glaucomatous young adults, and 2) to compare IOPs of pre-brisk walking with post brisk walking; IOPs post brisk walking with post recovery; and IOPs of pre-brisk walking with post recovery. This was an experimental study. Samples were taken purposively among the respondents consisting of students of the Nursing Program, Faculty of Medicine, University of Sam Ratulangi, that fulfiled the inclusion criteria wih 32 students. Data were collected during the pre and post 30-minute brisk walking, and 30 minutes post recovery. IOPs were measured with a Schiotz tonometer. Statistical analysis of data used the paired samples t-test with SPSS computer soft wear. The results showed that: 1) Brisk walking could reduce IOPs significantly $(\mathrm{p}<0.025)$; 2$)$ There were differences in IOPs between pre and post brisk walking (right eyes $2.6156 \pm 1.02110$ $\mathrm{mmHg}$; left eyes $2.3312 \pm 1.53464 \mathrm{mmHg}$ ); 3 ) There were differences in IOPs between post brisk walking and post recovery (right eyes $1.7781 \pm 0.91501 \mathrm{mmHg}$; left eyes $2.0344 \pm$ $1.69279 \mathrm{mmHg}$ ); and 4) There were more significant differences in IOPs between pre brisk walking and post recovery (right eyes $4.3937 \pm 1.20401 \mathrm{mmHg}$; left eyes $4.3656 \pm 2.01872$ $\mathrm{mmHg}$ ). Conclusion: brisk walking could reduce IOPs significantly at least until 30 minutes post recovery.
\end{abstract}

Keywords: brisk walking, IOPs

\begin{abstract}
Abstrak: Penelitian ini bertujuan untuk: 1) mengetahui pengaruh sesaat brisk walking terhadap penurunan tekanan intraokuler (TIO) pada orang dewasa muda non glaukoma, dan 2) membandingkan TIODS sesaat sebelum dan TIODS sesaat sesudah brisk walking; TIODS sesaat sesudah brisk walking dan TIODS post recovery; dan TIODS sesaat sebelum brisk walking dengan TIODS post recovery. Penelitian ini merupakan penelitian eksperimental. Sampel diambil secara purposive di antara populasi yang termasuk dalam mahasiswa semester 02 Program Studi Ilmu Keperawatan Fakultas Kedokteran Universitas Sam Ratulangi Manado yang memenuhi kriteria inklusi, yaitu sebanyak 32 orang. Data diambil pre-brisk walking, post brisk walking 30 menit dan post recovery 30 menit. Pengukuran TIO menggunakan tonometer Schiotz dan analisis data menggunakan uji-t sample berpasangan dengan perangkat lunak SPSS. Hasil penelitian yang diperoleh: 1) Brisk walking dapat menurunkan TIO secara bermakna ( $\mathrm{p}<0,025) ; 2)$. Terdapat perbedaan antara TIO mata kanan maupun kiri sebelum dan sesudah brisk walking (mata kanan 2,6156 $\pm 1,02110 \mathrm{mmHg}$; mata kiri 2,3312 \pm 1,53464 $\mathrm{mmHg}$ ); 3) Terdapat perbedaan antara TIO mata kanan maupun kiri sesudah brisk walking dan post recovery (mata kanan 1,7781 $\pm 0,91501 \mathrm{mmHg}$; mata kiri 2,0344 $\pm 1,69279$ $\mathrm{mmHg}$ ); dan 4) Terdapat perbedaan lebih bermakna antara TIO mata kanan maupun kiri sebelum brisk walking dibanding post recovery (mata kanan 4,3937 \pm 1,20401 $\mathrm{mmHg}$; mata kiri 4,3656 $\pm 2,01872 \mathrm{mmHg}$ ). Hasil penelitian ini menyimpulkan bahwa brisk walking secara bermakna dapat menurunkan TIO yang masih bertahan sampai 30 menit post recovery.
\end{abstract}

Kata kunci: briskwalking, TIO 
Keadaan tekanan intraokuler tinggi yang dikenal dengan sebutan glaukoma masih merupakan masalah yang serius hingga saat ini karena dapat menyebabkan kebutaan. Namun, kemyataannya ada juga kasus yang sama sekali tidak memberikan gejala apapun. ${ }^{1,2}$

Penanganan untuk menurunkan tekanan intraokuler yang tinggi yaitu dengan pemberian obat (untuk menghambat produksi humor akueus), hingga tindakan operatif atau pembedahan dari yang konvensional sampai pada yang menggunakan laser (agar pengaliran humor akueus menjadi lancar). Kedua jenis penanganan ini jelas memerlukan biaya yang cukup besar, padahal masih terdapat upaya pencegahan yang jauh lebih murah misalnya dengan berolahraga seperti yang telah diuji-cobakan di pusatpusat perawatan kesehatan. Beberapa penelitian di luar negeri tentang pengaruh aktivitas olah raga tertentu terhadap tekanan intraokuler menunjukkan perbedaan bermakna di antara sebelum dan sesudah berolah raga. ${ }^{3-5}$

Dari telusuran kepustakaan, penulis tidak menemukan penelitian tentang peran brisk walking (jalan dengan cara, waktu dan kecepatan tertentu) dalam hal menurunkan tekanan intraokuler orang nonglaukoma. Padahal olahraga ini merupakan aktivitas olah tubuh yang murah, mudah dan dengan risiko cidera yang sangat minimal. Hal-hal yang mengemuka di atas mendorong penulis melakukan penelitian tentang pengaruh sesaat brisk walking terhadap tekanan intraokuler orang nongalukoma. Hipotesis yang diajukan adalah: aktivitas brisk walking sesaat dapat menyebabkan penurunan tekanan intraokuler.

\section{HUMOR AKUEUS DAN TEKANAN INTRAOKULER}

Humor akueus merupakan cairan encer yang mengisi ruang kamera okuli anterior dan posterior bola mata. Pembentukan humor akueus oleh prosesus badan siliar terutama ditentukan oleh transportasi ion-ion secara aktif, dengan bahan pembentuk terpenting adalah bikarbonat. Selain itu pem- bentukan humor akueus juga terjadi dengan cara ultrafiltrasi cairan dari kapiler ke dalam mata. Proses ultrafiltrasi cairan ini dipengaruhi oleh tekanan hidrostatik dan proses difusi. ${ }^{6}$

Tekanan intraokuler (TIO) dipengaruhi oleh faktor pembentukan humor akueus, daya pengeluaran cairan bilik mata dan tekanan dalam vena episklera. TIO rata-rata pada manusia normal yang diukur pada posisi duduk dengan menggunakan tonometer Schiotz adalah $15,4 \mathrm{mmHg}$. TIO normal berkisar antara 15-21 mmHg diukur dengan tonometer Schiotz. Apabila tekanan intraokuler $22 \mathrm{mmHg}$, disebut suspek glaukoma. Beberapa penelitian mendapatkan TIO penderita glaukoma dapat mencapai $\geq 20$ $\mathrm{mmHg} .{ }^{2,3,5}$

TIO salah satunya ditentukan oleh pembentukan humor akueus yang berasal dari sekresi aktif ion natrium, kalium, bikarbonat dan ion lainnya dari epitel badan siliar. TIO dapat diturunkan dengan menurunkan $\mathrm{pH}$ darah dan menaikkan tekanan karbondioksida di dalam darah. ${ }^{7}$ Pada manusia telah dibuktikan penurunan jumlah produksi humor akueus sekitar 50\% dapat disebabkan oleh asidosis sistemik. ${ }^{8}$

Telah diketahui bahwa glaukoma dapat berakhir dengan kebutaan. Untuk mencegah terjadinya kebutaan diperlukan penanganan khusus, mulai dari pengobatan oral dengan obat penghambat produksi humor akueus sampai pengobatan operatif dari pembedahan konvensional hingga penggunaan laser untuk melancarkan aliran keluar humor akueus. Namun cara penanganan ini memerlukan biaya yang besar. ${ }^{1,2}$ Aktivitas fisik atau olahraga tertentu yang tidak memerlukan biaya mahal dapat menurunkan TIO, seperti latihan beban, jogging, lari dan jalan.

\section{TUJUAN PENELITIAN}

\section{Tujuan umum}

Untuk mengetahui pengaruh sesaat brisk walking terhadap penurunan tekanan intraokuler (TIO) pada orang dewasa muda nonglaukoma. 


\section{Tujuan khusus}

Untuk membandingkan:

a. Tekanan intraokuler dexter et sinister (TIODS) sesaat sebelum dan sesaat sesudah brisk walking selama 30 menit.

b. TIODS sesaat sesudah brisk walking dengan post recovery 30 menit.

c. TIODS sesaat sebelum brisk walking dengan post recovery 30 menit.

\section{MANFAAT PENELITIAN}

Brisk Walking diharapkan dapat menjadi terapi tambahan untuk menurunkan TIO yang tinggi pada penderita glaukoma dan sebagai pencegahan pada orang yang berpeluang menderita glaukoma.

\section{METODOLOGI PENELITIAN}

Penelitian ini merupakan penelitian eksperimental dan dilaksanakan di lintasan atletik lapangan KONI Sario Manado, pada bulan Agustus s/d November 2009.

Rancangan yang digunakan adalah one group pre-test - post test design.

Populasi adalah semua mahasiswa semester dua program studi Ilmu Keperawatan Fakultas Kedokteran Universitas Sam
Ratulangi Manado. Sampel adalah semua responden penelitian yang memenuhi kriteria inklusi (32 orang).

\section{Kriteria inklusi}

1. Orang dewasa muda usia 17-22 tahun (mahasiswa).

2. Bersedia mengikuti penelitian secara sukarela serta menandatangani informed consent.

3. Pada anamnesis dan pemeriksaan fisik tidak ditemukan: penyakit jantung, diabetes melitus, hipertensi (tekanan diastol $>90 \mathrm{mmHg}$ ), penyakit paru-paru menahun, gangguan kelenjar tiroid dan gangguan ekstremitas.

\section{Kriteria eksklusi}

Penderita glaukoma akut dan peningkatan TIO.

\section{Variabel}

Variabel independen: Brisk walking. Variabel dependen: Tekanan intra okuler (TIO).

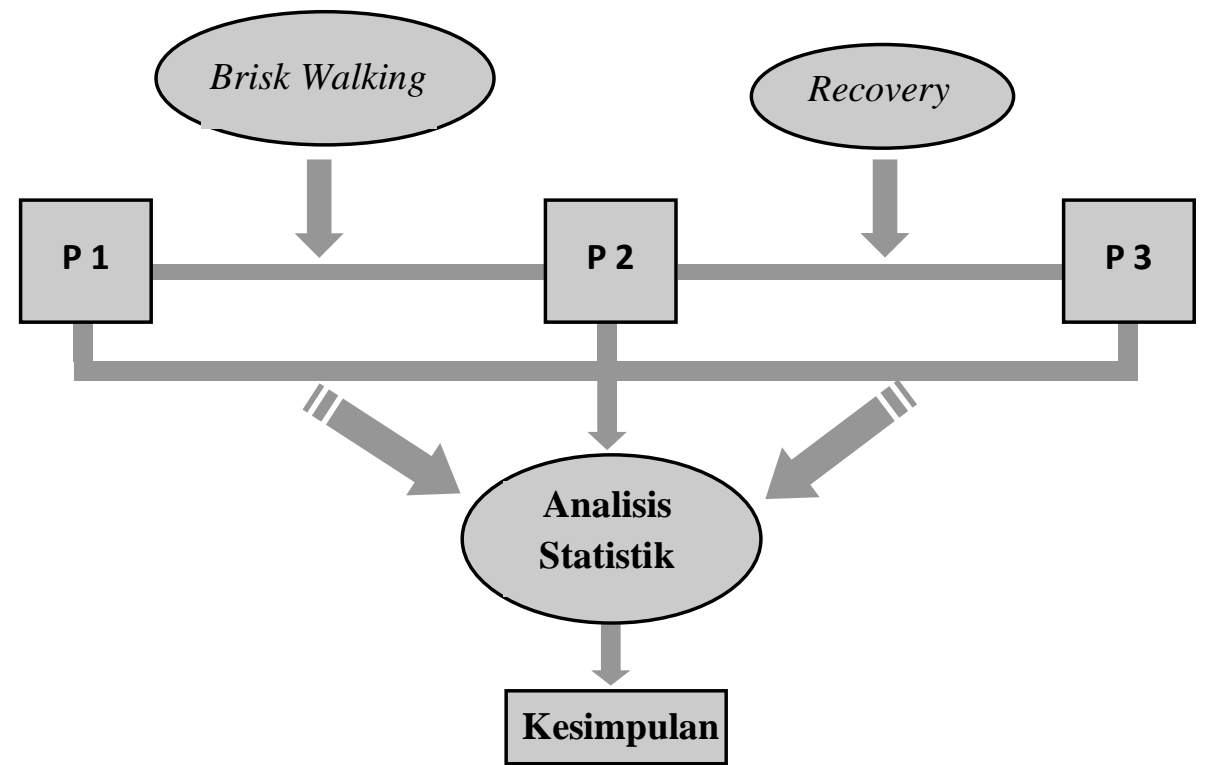

Gambar 1. Bagan rancangan penelitian. Keterangan: $\mathrm{P} 1=$ Pre-test $; \mathrm{P} 2=$ Post test $\mathrm{I} ; \mathrm{P} 3=$ Post test II (post recovery 30 menit). 


\section{Definisi operasional}

1. Brisk walking adalah aktivitas jalan yang lebih cepat dari biasanya yaitu dengan kecepatan 3-4 mil per jam (1 mil = $1,609 \mathrm{k} \mathrm{m})$, dengan lengan yang ditekuk pada sendi siku dengan sudut 90 derajat diayunkan dari samping tubuh ke depan melampaui ketinggian bahu dan dalam gerakan teratur. Pada saat melangkah tubuh dalam posisi tegak dan tumit yang lebih dulu menyentuh tanah diikuti oleh telapak kaki dan akhirnya ibu jari kaki yang menjadi tumpuan sebelum kaki yang lain melangkah ke depan dan dilakukan selama 30 menit.

2. Tekanan intraokuler (TIO) adalah tekanan bolamata dari subyek penelitian yang diukur dengan tonometer Schiotz. TIO normal berkisar antara $15-21 \mathrm{mmHg}$.

3. Orang dewasa muda adalah orang dewasa yang termasuk dalam kisaran usia 1739 tahun.

\section{Alat dan bahan}

Alat dan bahan penelitian yang digunakan adalah pengukur tekanan bolamata tonometer Schiotz, pengukur tekanan darah Nova Presameter Riester, timbangan berat badan Model HBF-356, pengukur tinggi badan ZT-120, pengukur indeks massa tubuh Model HBF-356, cairan anastesi topikal
Pantocain ${ }^{\circledR}$ tetes mata $0,5-1 \%$, stopwatch, alkohol $70 \%$ dan kapas steril.

\section{Analisis statistik}

Data dianalisis memakai uji t sampel berpasangan (paired samples t-test) dengan perangkat komputer program SPSS. ${ }^{9}$

\section{Alur Penelitian}

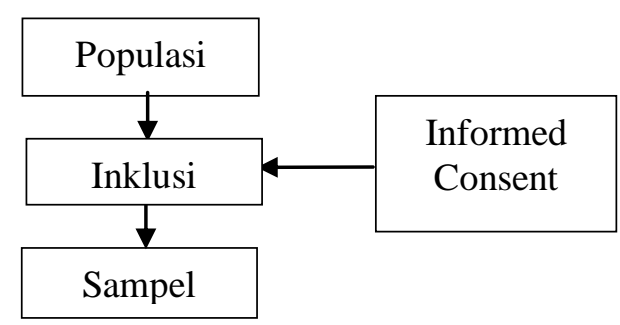

Gambar 2. Bagan kerangka prosedur penentuan sampel.

\section{HASIL PENELITIAN}

Tabel 1. Deskripsi TIO responden pada pengukuran TIOD dan TIOS pre-brisk walking, post brisk walking dan 30 menit post recovery

\begin{tabular}{lll}
\hline Aktivitas uji & $\begin{array}{l}\text { Rerata } \\
\text { TIOD }\end{array}$ & $\begin{array}{l}\text { Rerata } \\
\text { TIOS }\end{array}$ \\
\hline Pre-brisk walking & 19,4875 & 19,3594 \\
Post brisk walking & 16,8719 & 16,8469 \\
Post recovery & 15,0938 & 14,7156 \\
\hline
\end{tabular}

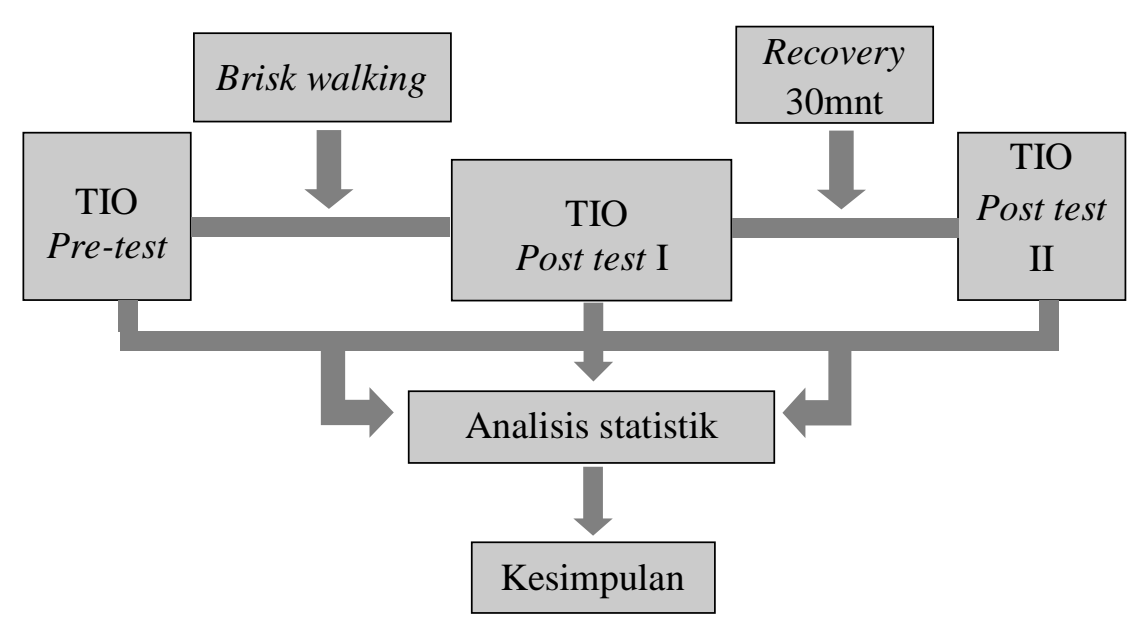

Gambar 3. Bagan kerangka jalannya penelitian dan pengolahan data hasil penelitian. Keterangan: TIO pre-test dibandingkan TIO post test I. TIO post test I dibandingkan TIO post test II. TIO pre test dibandingkan TIO post test II . 
Tabel 1 memperlihatkan rerata TIODS pada tiga aktivitas uji dengan penurunan rerata TIOD dan TIOS setelah aktivitas uji post brisk walking dan post recovery.

Hasil korelasi antara kedua variabel TIOD pre-brisk walking dan TIOD post brisk walking 0,722 dengan probabilitas sebesar 0,000. Hal ini berarti bahwa perbedaan di antara tekanan bola mata kanan sebelum jalan cepat (TIOD pre-brisk walking) dan sesudah jalan cepat (TIOD post brisk walking) sangat kuat dan sangat bermakna (Tabel 2). Juga untuk TIOS angka korelasi 0,691 dengan probabilitas sebesar 0,000 yang menunjukkan perbedaan yang sangat kuat dan bermakna (Tabel 2).

Hasil uji t sampel berpasangan (paired samples t-test) menunjukkan bahwa untuk TIOD nilai $t$ hitung adalah 14,490 dengan probabilitas 0,000 sedangkan untuk TIOS nilai $\mathrm{t}$ hitung 10,480 dengan probabilitas 0,000 (Tabel 3). Uji dilakukan dua sisi karena ingin diketahui apakah rerata sebelum sama dengan sesudah atau tidak.
Perlunya uji dua sisi bisa diketahui pula dari output SPSS yang menyebut adanya two tailed test (2-tailed). Untuk uji dua sisi, angka probabilitas adalah $0,000 / 2=0$. Oleh karena $0<0,025$, maka $\mathrm{H}_{1}$ diterima atau terdapat perbedaan bermakna di antara TIODS pre-brisk walking dan TIODS post brisk walking. Dengan kata lain brisk walking efektif dalam menurunkan TIO secara bermakna.

Dengan cara yang sama maka diperoleh hasil sebagai berikut: Terdapat perbedaan bermakna di antara: TIOD prebrisk walking (rerata 19,875) serta TIOS pre-brisk walking (rerata 19,3594) dibandingkan dengan TIOD post recovery (rerata 15,0938) dan TIOS pos trecovery (rerata 14,7156) (Tabel 1, 4 dan 5).

TIOD post brisk walking (rerata 16,8719) serta TIOS post brisk walking (rerata 16,8469) dibandingkan dengan TIOD post recovery (rerata 15,0938) dan TIOS post recovery (rerata 14,7156) (Tabel $1,6,7)$.

Tabel 2. Korelasi TIODS pre-brisk walking dan TIODS post brisk walking

\begin{tabular}{lccc}
\hline Pengukuran & Korelasi & Sig. & Keterangan \\
\hline TIOD pre-brisk walking dan TIOD post brisk walking & 0,722 & 0,000 & bermakna \\
TIOS pre-brisk walking dan TIOS post brisk walking & 0,691 & 0,000 & bermakna \\
\hline
\end{tabular}

Tabel 3. Nilai t hitung dan probabilitas pada pengukuran TIODS pre-brisk walking dan TIODS post brisk walking

\begin{tabular}{lccc}
\hline Pengukuran & t hitung & Sig. & Keterangan \\
\hline TIOD pre-brisk walking dan TIOD post brisk walking & 14,490 & 0,000 & bermakna \\
TIOS pre-brisk walking dan TIOS postbrisk Walking & 10,480 & 0,000 & bermakna \\
\hline
\end{tabular}

Tabel 4. Korelasi TIODS pre-brisk walking dan TIODS post recovery

\begin{tabular}{cccc}
\hline Pengukuran & Korelasi & Sig. & Keterangan \\
\hline TIOD pre-brisk walking dan TIOD post recovery & 0,658 & 0,000 & bermakna \\
TIOS pre-brisk walking dan TIOS post recovery & 0,444 & 0,011 & bermakna \\
\hline
\end{tabular}

Tabel 5. Nilai t hitung dan probabilitas pada pengukuran TIODS pre-brisk walking dan TIODS post recovery

\begin{tabular}{lccc}
\hline Pengukuran & t hitung & Sig. & Keterangan \\
\hline TIOD pre-brisk walking dan TIOD post recovery & 20,643 & 0,000 & bermakna \\
TIOS pre-brisk walking dan TIOS post recovery & 15,441 & 0,000 & bermakna \\
\hline
\end{tabular}


Tabel 6. Korelasi TIODS post brisk walking dan TIODS post recovery

\begin{tabular}{lccc}
\hline Pengukuran & Korelasi & Sig. & Keterangan \\
\hline TIOD post brisk walking dan TIOD post recovery & 0,768 & 0,000 & bermakna \\
TIOS post brisk walking dan TIOS post recovery & 0,514 & 0,003 & bermakna \\
\hline
\end{tabular}

Tabel 7. Nilai t hitung dan probabilitas pada pengukuran TIODS post brisk walking dan TIODS post recovery

\begin{tabular}{lccc}
\hline Pengukuran & t hitung & Sig. & Keterangan \\
\hline TIOD post brisk walking dan TIOD post recovery & 10,993 & 0,000 & bermakna \\
TIOS post brisk walking dan TIOS post recovery & 7,139 & 0,000 & bermakna \\
\hline
\end{tabular}

\section{Anilisis satistik pengaruh brisk walking terhadap tekanan intraokuler (TIO)}

Nilai TIO kedua mata sesudah brisk walking menurun secara bermakna $(\mathrm{p}<0,05)$ dibandingkan dengan nilai TIO sebelum brisk walking. Hal ini tampak pada hasil rerata TIO sebelum brisk walking sebesar 19,4875 $\pm 1,4727 \mathrm{mmHg}$ dan sesudah brisk walking $16,8719 \pm 1,13144 \mathrm{mmHg}$ untuk mata kanan $(2,6156 \pm 1,02110 \mathrm{mmHg})$, sedangkan untuk mata kiri sebelum brisk walking sebesar 19,3594 \pm 1,62061 $\mathrm{mmHg}$ dan sesudah brisk walking 16,8469 \pm $1,80179 \mathrm{mmHg} \quad(2,51250 \pm 1,53464$ $\mathrm{mmHg}$ ). Keadaan ini mengandung arti bahwa brisk walking secara bermakna dapat menurunkan TIO (Tabel 1, 2, 3).

Nilai TIO kedua mata sesudah istirahat 30 menit (post recovery) menurun secara bermakna $(\mathrm{p}<0,05)$ dibandingkan dengan sesudah brisk walking 30 menit, seperti tampak pada hasil rerata TIO sesudah brisk walking sebesar $16,8719 \pm 1,13144 \mathrm{mmHg}$ dan sesudah istirahat 30 menit 15,0938 \pm $1,42737 \mathrm{mmHg}$ untuk mata kanan $(1,7781 \pm$ $0,91501 \mathrm{mmHg}$ ), sedangkan untuk mata kiri sebesar 16,8469 $\pm 1,80179 \mathrm{mmHg}$ sesudah brisk walking dan 14,7156 $\pm 1,60706$ $\mathrm{mmHg}$ sesudah istirahat 30 menit $(2,13125$ $\pm 1,68876 \mathrm{mmHg}$ ). Hal ini menunjukkan bahwa nilai TIO kedua mata sesudah istirahat 30 menit jauh lebih rendah dibandingkan dengan nilai TIO sesudah brisk walking 30 menit (Tabel 1, 6, 7).

Nilai TIO kedua mata sesudah istirahat selama 30 menit menurun sangat bermakna $(\mathrm{p}<0,05)$ jika dibandingkan dengan TIO sebelum brisk walking. Hal ini terlihat jelas pada hasil rerata TIOD sebelum brisk walking sebesar 19,4875 $\pm 1,4727 \mathrm{mmHg}$ dan sesudah istirahat 30 menit 15,0938 \pm 1,42737 mmHg $(4,3937 \pm 1,20401 \mathrm{mmHg})$, sedangkan untuk TIOS sebelum brisk walking sebesar 19,3594 $\pm 1,62061 \mathrm{mmHg}$ dan $14,7156 \pm 1,60706 \mathrm{mmHg}$ sesudah istirahat 30 menit $(4,6437 \pm 1,70122$ mmHg) (Tabel 1, 4, 5). Dengan kata lain, nilai TIO kedua mata sesudah istirahat 30 menit jauh lebih rendah jika dibandingkan dengan nilai TIO sebelum melakukan aktivitas brisk walking.

\section{BAHASAN}

TIO dipengaruhi oleh faktor pembentukan cairan bilik mata, daya pengeluaran cairan bilik mata dan tekanan dalam vena episklera. Sedangkan bahan pembentuk cairan bola mata adalah bikarbonat yang pada kegiatan brisk walking menjadi berkurang akibat digunakannya bikarbonat pada keadaan penurunan $\mathrm{pH}$ darah.

Hasil penelitian ini sesuai dengan penelitian Qureshi tahun $1995^{3}$, yang menemukan bahwa setelah orang coba sehat maupun yang mengidap glaukoma melakukan olah raga angkat beban, jogging dan lari dengan intensitas tertentu, ternyata terdapat perbedaan TIO yang bermakna pada saat sebelum dan sesudah latihan fisik. Begitu pula penelitian Passo $\mathrm{dkk}^{10}$ mendapatkan TIO pada orang normal menurun sebesar $4 \mathrm{mmHg}$ setelah melakukan latihan aerobik dengan sepeda ergometrik satu jam setiap minggu selama tiga bulan. Hasil penelitian ini juga 
sesuai dengan penelitian Qureshi tahun $1996^{11}$ pada orang normal yang melakukan latihan angkat beban dengan tujuan menjaga kebugaran 20 menit per hari selama empat hari dan mendapatkan penurunan TIO kirakira $4 \mathrm{mmHg}$.

Karabatakis $\mathrm{dkk}^{12}$ juga telah meneliti pengaruh olahraga jogging terhadap TIO pada 29 orang dewasa normal, yang terdiri dari 25 orang atlit dan empat subyek non atlit. Bentuk olahraganya adalah jogging selama 25 menit pada beban submaksimal $(75 \%)$. Hasilnya menunjukkan terjadi penurunan TIO pada kedua mata sebagian besar orang coba, dimana hanya tiga orang yang tidak mengalami penurunan TIO. Penurunan TIO berkisar antara 1-8 $\mathrm{mmHg}$, dimana secara statistika penurunan ini sangat bermakna $(\mathrm{p}<0.01)$.

Hasil yang sesuai juga ditemukan oleh Kiuchi dkk ${ }^{13}$ yang meneliti pengaruh beban dan lamanya aktivitas fisik terhadap penurunan TIO pada responden sehat dan terlatih secara fisik. Lima menit sesudah responden melakukan aktivitas fisik selama 15 menit pada beban $70 \%, 55 \%$ dan $40 \%$ dari prosentase denyut jantung (Hrmax), TIO menurun masing-masing sebesar 4,3 $\pm 0,7 \mathrm{mmHg}$, $2,2 \pm 0,7 \mathrm{mmHg}$ dan $0,6 \pm 0,5 \mathrm{mmHg}$. Berlari selama 7,5 menit dengan $70 \%$ Hrmax menurunkan TIO sebanding dengan berlari selama 15 menit dengan beban yang sama $(4,4 \pm 0,6 \mathrm{mmHg})$. Duapuluh lima menit berlari dengan beban $40 \%$ HRmax sebanding dengan 15 menit berlari pada $70 \%$ HRmax. Kiuchi dkk menyimpulkan bahwa besarnya penurunan TIO setelah berolahraga tergantung pada intensitas atau kekuatan melakukan olahraga, bukan oleh karena lama dan kuantitas olahraga.

\section{SIMPULAN}

Hipotesis dapat diterima berdasarkan simpulan hasil analisis sebagai berikut:

1. Brisk walking sesaat dapat menurunkan TIO secara bermakna.

2. Ada perbedaan TIO sebelum brisk walking dan sesudah brisk walking 30 menit pada kedua mata, atau dengan kata lain brisk walking efektif dalam menurunkan TIO secara bermakna pada kasus sebelum dan sesudah brisk walking.

3. Ada perbedaan TIO sesudah brisk walking 30 menit dan sesudah istirahat 30 menit pada kedua mata, atau dengan kata lain brisk walking efektif dalam menurunkan TIO secara bermakna pada kasus sesudah brisk walking dan sesudah istirahat 30 menit.

4. Ada perbedaan sangat bermakna pada TIO sebelum brisk walking dibanding sesudah istirahat selama 30 menit pada kedua mata, atau dengan kata lain brisk walking efektif dalam menurunkan TIO secara bermakna pada kasus sebelum brisk walking dan sesudah istirahat selama 30 menit.

\section{SARAN}

1. Brisk walking dapat dipikirkan untuk digunakan sebagai terapi tambahan pada penderita glaukoma, untuk itu diperlukan penelitian lanjut.

2. Brisk walking dapat dipikirkan juga untuk digunakan sebagai pencegahan pada orang yang berpeluang menderita glaukoma.

3. Disarankan untuk penelitian lanjut dapat dilakukan program latihan long-term exercise agar dapat menilai perubahan tekanan intraokuler yang bukan hanya berdasarkan pada perubahan biokimiawi tubuh melainkan juga berdasarkan pada perubahan fisiologis tubuh manusia.

4. Pada penelitian selanjutnya dapat dilakukan pengukuran faktor ataupun variabel lain yang memengaruhi tekanan intraokuler seperti daya pengeluaran humor akueus dan tekanan episklera, sehingga dapat diketahui faktor-faktor yang lebih besar pengaruhnya terhadap tekanan intraokuler.

5. Untuk penelitian selanjutnya sebaiknya subyek diisolasi beberapa hari sebelum dan selama pegambilan data supaya aktivitas fisiknya dapat terkontrol dengan baik sehingga pelaksanaannya benar-benar mengakibatkan perubahan fisiologis tu- 
buh untuk dapat menurunkan tekanan intraokuler.

\section{DAFTAR PUSTAKA}

1. Silverthorn DU. Human Physiology: An integrated approach (Fourth Edition). San Fransisco: Pearson Education Inc., 2007.

2. Ilyas S. Ilmu Penyakit Mata (Edisi 3). Jakarta: FKUI Press, 2004.

3. Qureshi IA. The effect of mild, moderate, and severe exercise on intraocular pressure in glaucoma patients. Jpn J Physiol. 1995;45(4):561-9.

4. Kielar RA, Teraslinna P, Rowe DG, Jackson J. Standarized aerobic and anaerobic exercise: Differential effects on intraocular tension, blood $\mathrm{pH}$, and lactate. Invest Ophthalmol. 1975;14(10):782-5.

5. Avunduk AM, Yilmas B, Zahin N, Kapizioglu. The comparison of intraocular pressure reduction after isometric and isokinetic exercises in normal individuals. Ophthalmologica 1999;213(5):290-4.

6. Moses AR. Adler's Physiology of the Eye Clinical Application (Eight Edition). St. Louis: Mosby, 1987.

7. Hall JE. Fluid system of the eye-intraocular fluid. In: Guyton AC, Hall JE, editors.
Review of Medical Physiology (Ninth Edition). Philadelphia: WB Saunders Co., 1996; p. 642-55.

8. Hoskins HD, Kass MA. Intraocular pressure In: Becker, Shaffers. Diagnosis and Therapy of Glaucomas (Seventh Edition). St. Louis: Mosby, 1999; p. 6579.

9. Santoso S. Menguasai Statistik di Era Informasi dengan SPSS 14. Jakarta: PT Elex Media Komputindo Kelompok Gramedia, 2006.

10. Passo MS, Golberg L, Eliot DL, Michael EVB. Exercise conditioning and intraocular pressure. Am J Ophthalmol. 1987;103:754-7.

11. Qureshi IA. Effects of exercise on intraocular pressure in physically fit subjects. Clin Exp Pharmacol Physiol. 1996;23(8):648-52.

12. Karabatakis VE, Natsis KI, Chatzibalis TE, Lake SL, Bisbas IT, Kaliandris. Correlating intraocular pressure, blood pressure, and heart rate changes after jogging. Eur J Ophthalmol 2004;14(2):117-22.

13. Kiuchi Y, Mishiam HK, Hotema Y, Furomoto A, Hirota A, Onri IC. Exercise intensity determines the magnitude of IOP decrease after running. Jpn J Ophthalmol. 1994;38(2):191-5. 